\title{
Poor prognosis in cholangiocarcinoma patients with low FBXW7 expression is improved by chemotherapy
}

\author{
NORIHIRO ISHII ${ }^{1,2}$, KENICHIRO ARAKI $^{1,2}$, TAKEHIKO YOKOBORI $^{3}$, AKIRA WATANABE $^{1,2}$, \\ MARIKO TSUKAGOSHI ${ }^{1,2}$, NORIO KUBO ${ }^{1,2}$, HIDEKI SUZUKI ${ }^{1}$, FUMIYOSHI SAITO ${ }^{1,2}$, \\ BOLAG ALTAN $^{1}$, YASUO HOSOUCHI ${ }^{4}, \mathrm{KEN} \mathrm{SHIRABE}^{2 *}$ and HIROYUKI KUWANO ${ }^{1 *}$
}

\begin{abstract}
Departments of ${ }^{1}$ General Surgical Science, ${ }^{2}$ Hepatobiliary and Pancreatic Surgery and ${ }^{3}$ Molecular Pharmacology and Oncology, Gunma University, Graduate School of Medicine, Maebashi, Gunma 371-8511; ${ }^{4}$ Department of Surgery and Laparoscopic Surgery, Gunma Prefecture Saiseikai-Maebashi Hospital, Maebashi, Gunma 371-0821, Japan
\end{abstract}

Received March 30, 2016; Accepted February 1, 2017

DOI: $10.3892 / 01.2017 .5946$

\begin{abstract}
The tumor suppressor FBXW7 has been demonstrated to degrade several oncoproteins, including c-Myc. Although low FBXW7 expression levels are suggested to be a poor prognostic factor in a number of types of solid tumor, the role of FBXW7 in chemosensitivity is controversial. The purpose of the present study was to determine whether FBXW7 expression may be used as a marker for poor prognosis and chemosensitivity in patients with cholangiocarcinoma (CC). FBXW7 expression was investigated by immunohistochemistry in 100 surgically resected CC samples, and the association between FBXW7 expression, clinicopathological factors and prognosis was evaluated. Nuclear FBXW7 expression tended to be lower compared with normal tissues. A total of 54 patients exhibited high expression levels of FBXW7, and 46 patients exhibited low expression levels. Patients with low FBXW7 expression possessed significantly larger tumors $(\mathrm{P}=0.049)$, enhanced expression of $\mathrm{c}-\mathrm{Myc}$ and $\mathrm{Ki}-67$ and significantly poorer prognoses compared with those with high FBXW7 expression $(\mathrm{P}=0.016)$. Multivariate analysis revealed that low FBXW7 expression was an independent negative prognostic factor in $\mathrm{CC}(\mathrm{P}=0.043)$. In patients with high FBXW7 expression levels, the cancer-specific survival times were not significantly different between patients with or without chemotherapy. However, in patients with low FBXW7
\end{abstract}

Correspondence to: Dr Takehiko Yokobori, Department of Molecular Pharmacology and Oncology, Gunma University, Graduate School of Medicine, 3-39-22 Showamachi, Maebashi, Gunma 371-8511, Japan

E-mail: bori45@gunma-u.ac.jp

${ }^{*}$ Contributed equally

Abbreviations: CC, cholangiocarcinoma; FBXW7, F-box and WD repeat domain-containing 7; TNM, tumor-node-metastasis

Key words: tumor suppressor, tumor progression, ubiquitin ligase, chemosensitivity, c-Myc expression levels, the cancer-specific survival times were significantly longer in subjects who underwent chemotherapy compared with those who did not $(\mathrm{P}=0.001)$. These data suggest that FBXW7 status in CC is a useful predictor of poor prognosis and cancer progression. Additionally, FBXW7 may be a surrogate marker to predict the efficacy of chemotherapy in $\mathrm{CC}$.

\section{Introduction}

The incidence of cholangiocarcinoma (CC), which is a major cause of cancer-associated mortality in Asia, is rising worldwide (1). Despite recent advances in cancer therapy, it is difficult to completely cure $\mathrm{CC}$ as radical surgical resection is the only effective curative treatment (2). Additionally, chemotherapy regimens for patients with $\mathrm{CC}$ with recurrent and metastatic lesions have been insufficient. However, small populations of patients with CC have obtained significant benefits from conventional chemotherapy $(3,4)$. Therefore, to improve patient prognoses and risk assessments, additional studies are required to identify novel markers and therapeutic targets.

F-box and WD repeat domain-containing 7 (FBXW7), which is an F-box protein consisting of 1 of the 4 subunits of the Skp Cullin F-box containing ubiquitin ligase complex, induces the degradation of oncoproteins including c-Myc, CyclinE, mammalian target of rapamycin (mTOR), Notch and myeloid cell leukemia 1 (MCL1) via ubiquitin-mediated degradation pathways $(5,6)$. The degradation of c-Myc by FBXW7 leads to cell cycle dormancy or the G0 state, therefore, FBXW7 alteration serves an important role in, and is a major cause of, carcinogenesis (7). Takeishi et al (8) revealed that ablation of the $F B X W 7$ gene in mouse leukemia-initiating cells of chronic myeloid leukemia induced cell cycle re-entry via accumulation of c-Myc, and subsequently increased the sensitivity of the cells to chemotherapy. Concomitantly, it is known that loss of FBXW7 function is associated with resistance to anti-tubulin agents via the accumulation of the anti-apoptotic protein MCL1, a member of the B-cell lymphoma 2 family (9). Therefore, the role of FBXW7 in chemosensitivity is controversial. 
In a previous study of clinical samples, low FBXW7 expression levels were associated with poor prognosis and cancer progression in a number of human malignancies including breast cancer (10), hepatocellular (11) and esophageal carcinoma $(12,13)$. In intrahepatic and perihilar CC, it was demonstrated that low FBXW7 expression levels are associated with cancer progression and the increase of migration and invasion rates due to the accumulation of mTOR, an FBXW7 degradation target, as demonstrated in vivo and in vitro (14). Furthermore, Enkhbold et al (15) revealed that low FBXW7 expression levels in clinical samples of intrahepatic CC were associated with significantly poor prognosis, although their number of cases was small. However, few studies have addressed the role of FBXW7 in the prognosis and chemosensitivity of patients with $\mathrm{CC}$, whether intrahepatic or extrahepatic disease.

The purpose of the present study was to determine the clinical significance of FBXW7 expression in CC. The expression levels of FBXW7 were investigated in CC tissue samples using immunohistochemistry to evaluate whether this protein qualifies as a marker of poor prognosis and chemosensitivity for patients with this disease.

\section{Materials and methods}

Patients and samples. A total of 100 patients with CC who underwent surgical resection at the Gunma University Hospital (Maebashi, Japan) and the Gunma Prefecture Saiseikai-Maebashi Hospital (Maebashi, Japan) between January 1996 and December 2011 were included in the present study. There were 69 males and 31 females. The mean age of patients was 68.1 years, range, 36-94 years. Intra- and extrahepatic CC were diagnosed in 14 and 86 patients, respectively. Operative procedures were as follows: Among patients diagnosed with intrahepatic CC, 11 underwent right or left hepatectomy and 3 underwent sectionectomy, and among those diagnosed with extrahepatic $\mathrm{CC}, 14$ underwent hepatectomy with bile duct resection, 63 underwent pancreatoduodenectomy, 3 underwent hepato-pancreatoduodenectomy and 6 underwent bile duct resection alone. For all cases, lymph node dissection was performed according to the location of the tumor. The median follow-up period for survivors was 30.4 months, range, 2.2-115.2 months. The pathological stage of $\mathrm{CC}$ was determined according to the 7th edition of tumor-node-metastasis (TNM) classification of Union for International Cancer Center (16). A total of 80 patients were staged as R0, no local residual tumor, and 20 patients were staged as R1, microscopic residual tumor. Recurrence occurred in 56 patients, while 64 patients received chemotherapy. Chemotherapy was recommended for all patients, however, those with dysfunction of the vital organs and those who chose not to receive chemotherapy were excluded. The details of chemotherapy are as follows: 30 patients received tegafur/gimeracil/oteracil (S-1), 24 received gemcitabine, 17 received tegafur-uracil, 7 received gemcitabine $+\mathrm{S}-1$, and 2 received gemcitabine + cisplatin, including overlap. None of the patients had received neoadjuvant chemotherapy and irradiation prior to surgical resection. Patient backgrounds are summarized in Table I. Written informed consent was obtained from all patients included in the present study, which was approved by the institutional review board at Gunma University Hospital.
Immunohistochemical staining. A paraffin-embedded block of $\mathrm{CC}$ specimens was cut into $2-\mu \mathrm{m}$ thick sections and mounted on glass slides. Each section was deparaffinized by xylene and dehydrated in alcohol. Endogenous peroxidase was inhibited using $0.3 \% \mathrm{H}_{2} \mathrm{O}_{2} /$ methanol for $30 \mathrm{~min}$ at room temperature. The sections were soaked in heated water with $0.5 \%$ Immunosaver (Nisshin EM Co. Ltd., Tokyo, Japan) at $98^{\circ} \mathrm{C}$ for $45 \mathrm{~min}$. Non-specific antigens were blocked by Protein Block, Serum-Free (Dako; Agilent Technologies, Inc., Santa Clara, CA, USA) at room temperature for $30 \mathrm{~min}$. The sections were then incubated with rabbit polyclonal primary antibody against FBXW7 (cat. no., ab109617; dilution, 1:300; Abcam, Cambridge, MA, USA) for $24 \mathrm{~h}$ at $4^{\circ} \mathrm{C}$. Subsequent to washing in PBS, the Histofine Simple Stain MAX-PO (MULTI) kit (Nichirei Biosciences, Inc., Tokyo, Japan) was applied for visualizing primary antibody and incubated at room temperature for $45 \mathrm{~min}$. The chromogen 3,3'-diaminobenzidine tetrahydrochloride (DAB) was applied as a $0.02 \%$ solution containing $0.005 \% \mathrm{H}_{2} \mathrm{O}_{2}$ in $50 \mathrm{mM}$ ammonium acetate-citrate acid buffer ( $\mathrm{pH}$ 6.0). Finally, counterstaining of the nucleus was performed using Mayer's hematoxylin solution. A negative control was included by replacing the primary antibody with PBS in $0.1 \%$ bovine serum albumin, and confirmed no detectable staining in this case.

Additionally, 3 sequential sections of each sample were treated with primary antibodies against c-Myc (cat. no., ab32072; dilution, 1:50; Abcam) and the cell proliferation marker Ki-67 (cat. no., M7240; dilution, 1:150; Dako; Agilent Technologies, Inc.), according to the aforementioned protocol, to evaluate the correlations between FBXW7, c-Myc and cell proliferation.

Assessment of $F B X W 7$ and c-Myc expression. Nuclear staining of FBXW7 in cancerous tissue was evaluated in 5 randomly selected fields, and the intensity scored. The intensity score ranged from 1 to 3 , with 1 , weak; 2 , moderate; and 3 , strong, and was evaluated in each sample.

The expression level of c-Myc was evaluated in the nucleus of the cancerous tissue. The proportion of positively staining tumor cells was evaluated, regardless of the staining intensity. A percentage of positive tumor cells $\geq 10 \%$ was defined as 'positive' expression and $<10 \%$ was defined as 'negative' expression (17).

Statistical analysis. Data for the continuous variables were expressed as the mean \pm standard deviation, or median and range. The association between FBXW7 expression and clinicopathological characteristics was analyzed using the $\chi^{2}$ test and the Wilcoxon signed-rank test. Survival curves were described using the Kaplan-Meier method, and differences in survival between groups were compared using the log-rank test. Univariate and multivariate analysis by the Cox proportional hazards model was used to identify prognostic factors. $\mathrm{P}<0.05$ was considered to indicate a statistically significant difference. All statistical analyses were performed using the JMP software package (version 10.0.0; SAS Institute Inc., Cary, NC, USA).

\section{Results}

Analysis of FBXW7 expression in CC tissues by immunohistochemistry. FBXW7 expressed in the nucleus was measured 
by immunohistochemistry. Therefore, nuclear FBXW7 expression was evaluated in $100 \mathrm{CC}$ samples. FBXW7 expression was observed in normal bile duct epithelium (Fig. 1A); however, the expression was lower in cancerous areas (Fig. 1B and C). Similarly, FBXW7 expression was reduced at the site of lymph node metastases (Fig. 1E and F). These CC samples were divided into 2 groups according to the intensity of nuclear FBXW7 staining in the cancerous areas. A score of 1 in cancerous tissue samples was considered a low expression level of FBXW7 (Fig. 1B and C); scores of 2 or 3 were considered as high expression (Fig. 1D). A total of 54 samples exhibited high FBXW7 expression, whilst 46 exhibited low FBXW7 expression. Additionally, the correlation among FBXW7, c-Myc and marker of proliferation Ki67 (Ki-67) expression was investigated using immunohistochemistry in 3 sequential sections (Fig. 2). Low FBXW7 expression samples demonstrated enhanced expression of c-Myc and Ki-67 (Fig. 2A), while high FBXW7 expression samples exhibited lower expression of c-Myc and Ki-67 (Fig. 2B). Low FBXW7 expression was significantly associated with nuclear c-Myc accumulation $(\mathrm{P}<0.001)$.

Association between FBXW7 expression and clinicopathological characteristics of $C C$. The clinicopathological characteristics of patients listed according to FBXW7 expression are summarized in Table II. Low FBXW7 expression levels were significantly associated with progressive tumor size $(\mathrm{P}=0.049)$. Furthermore, the median recurrence-free survival time of the low FBXW7 expression group was significantly shorter compared with that of the high FBXW7 expression group $(\mathrm{P}=0.044)$. However, there were no significant differences with respect to age, sex, histology, tumor stage, lymph node metastasis, recurrence and chemotherapy.

Prognostic value of FBXW7 expression in CC. Patients with low FBXW7 expression exhibited significantly poorer prognoses compared with those with high FBXW7 expression in terms of overall and cancer-specific survival $(\mathrm{P}=0.016$ and $\mathrm{P}=0.007$, respectively; Fig. 3A and $\mathrm{B}$ ). Notably, even in cases of negative lymph node metastasis, the low FBXW7 expression group also exhibited significantly poorer prognosis compared with the high FBXW7 expression group for overall survival $(\mathrm{P}=0.032$; Fig. 3C). The association between FBXW7 expression and survival subsequent to chemotherapy was also examined. In the high FBXW7 expression group, cancer-specific survival times were not significantly different among patients with or without chemotherapy (Fig. 3D). In the low FBXW7 expression group, however, cancer-specific survival times in patients who received chemotherapy were significantly longer compared with that of patients who did not $(\mathrm{P}=0.001$; Fig. 3D). Due to various chemotherapy regimens in the cohort of the present study, a sub-analysis was performed according to chemotherapy regimen, such as $\mathrm{S}-1$, gemcitabine, and tegafur-uracil. However, each regimen demonstrated similar results, and there were no significant differences between the regimens (data not shown). Additionally, the present study considered whether differences in patient characteristics, including exhibiting a more aggressive-stage tumor, may explain the difference in survival outcomes between patients with low FBXW7-expression who underwent chemotherapy compared
Table I. Patient characteristics.

\begin{tabular}{|c|c|}
\hline Factors & Number \\
\hline Age (mean \pm standard deviation) & $68.1 \pm 9.0$ \\
\hline \multicolumn{2}{|l|}{ Sex } \\
\hline Male & 69 \\
\hline Female & 31 \\
\hline \multicolumn{2}{|l|}{ Location } \\
\hline Intrahepatic & 14 \\
\hline Extrahepatic & 86 \\
\hline \multicolumn{2}{|l|}{ Histology } \\
\hline Well & 21 \\
\hline Moderate & 49 \\
\hline Poor & 30 \\
\hline \multicolumn{2}{|l|}{ Tumor size (mm) } \\
\hline$\leq 60$ & 84 \\
\hline$>60$ & 9 \\
\hline N/A & 7 \\
\hline \multicolumn{2}{|l|}{ Tumor stage } \\
\hline $\mathrm{T} 1, \mathrm{~T} 2$ & 47 \\
\hline $\mathrm{T} 3, \mathrm{~T} 4$ & 53 \\
\hline \multicolumn{2}{|l|}{ Lymph node metastasis } \\
\hline Absent & 58 \\
\hline Present & 42 \\
\hline \multicolumn{2}{|l|}{ Stage (UICC) } \\
\hline $0, \mathrm{I}, \mathrm{II}$ & 77 \\
\hline III, IV & 23 \\
\hline \multicolumn{2}{|l|}{ Recurrence } \\
\hline Absent & 44 \\
\hline Present & 56 \\
\hline \multicolumn{2}{|l|}{ Chemotherapy } \\
\hline Absent & 36 \\
\hline Present & 64 \\
\hline
\end{tabular}

SD, standard deviation; UICC, Union for International Cancer Control; N/A, not available.

with those who did not. However, no such differences were observed (Table III). These data therefore suggest that patients with low FBXW7 expression are sensitive to chemotherapy compared with patients with high FBXW7 expression.

Univariate and multivariate analyses of overall survival are summarized in Table IV. Low FBXW7 expression was a prognostic factor on univariate analysis, including with histology, tumor stage, lymph node metastasis and recurrence. However, on multivariate analysis, only low FBXW7 expression in CC was an independent poor prognostic factor, thus outweighing the existing clinicopathological factors for overall survival in the cohort of the present study $(\mathrm{P}=0.043)$.

\section{Discussion}

In the present study, it was demonstrated that low FBXW7 expression levels in the nucleus are associated with tumor 
A

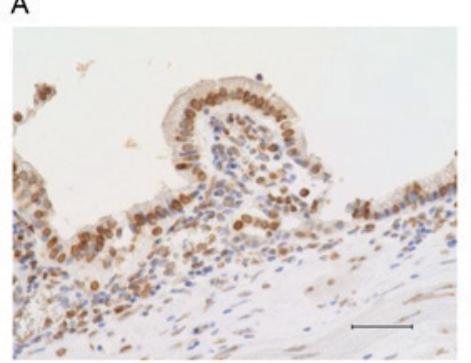

D

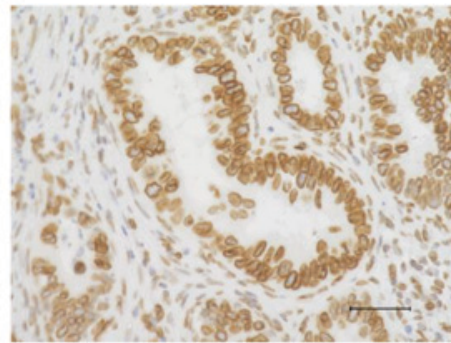

B

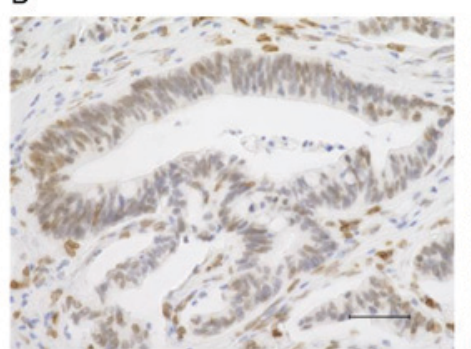

$\mathrm{E}$

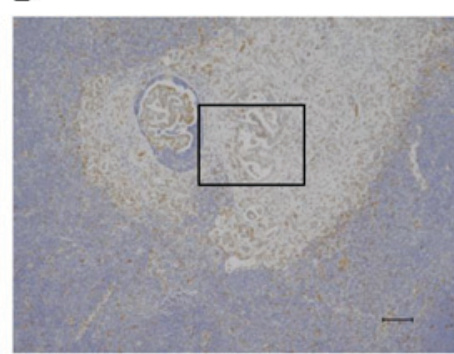

C

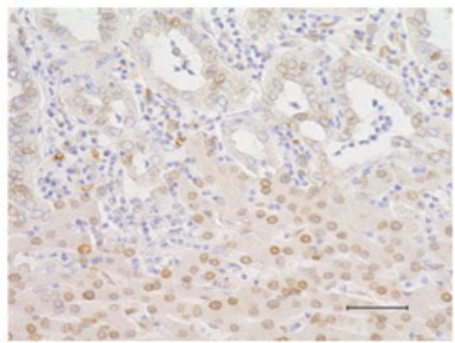

$\mathrm{F}$

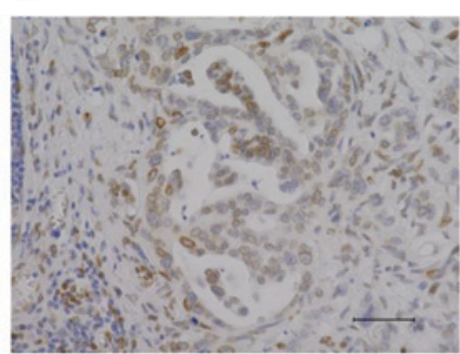

Figure 1. Immunohistochemical staining of FBXW7. (A) FBXW7 expression in normal bile duct epithelium (magnification, $\mathrm{x} 400$; scale bar, $50 \mu \mathrm{m}$ ). (B) Representative extrahepatic CC sample demonstrating weak expression of FBXW7 (magnification, x400; scale bar, $50 \mu$ m). (C) Representative intrahepatic CC sample that demonstrates weak expression of FBXW7 (magnification, x200; scale bar, $100 \mu \mathrm{m}$ ). (D) Representative extrahepatic CC sample demonstrating strong expression of FBXW7 (magnification, x400; scale bar, $50 \mu \mathrm{m}$ ). (E) FBXW7 expression in a lymph node metastasis of CC on a low power field (magnification, x100; scale bar $100 \mu \mathrm{m}$ ). (F) High power field of Fig. 1E (square); the lymph node metastasis site of CC demonstrated low expression of FBXW7 (magnification, $\mathrm{x} 400$; scale bar, $50 \mu \mathrm{m}$ ). Immunohistochemical staining was performed using 3,3'-diaminobenzidine and counterstaining of the nucleus was performed using Mayer's hematoxylin solution. All bright images were obtained using a fluorescence microscope (BZ-X700, KEYENCE, Osaka, Japan) FBXW7, F-box and WD repeat domain-containing 7; CC, cholangiocarcinoma.

A

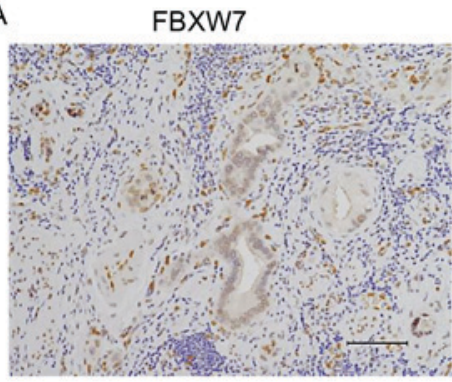

B

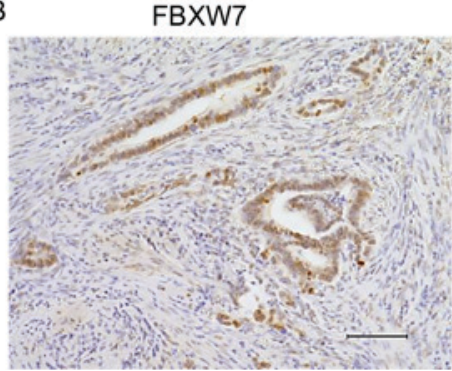

c-Myc

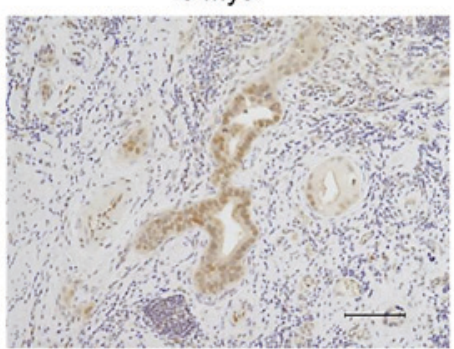

c-Myc

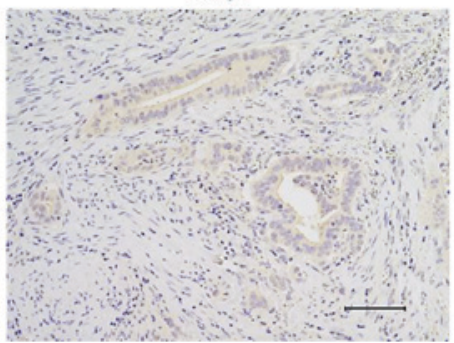

Ki-67

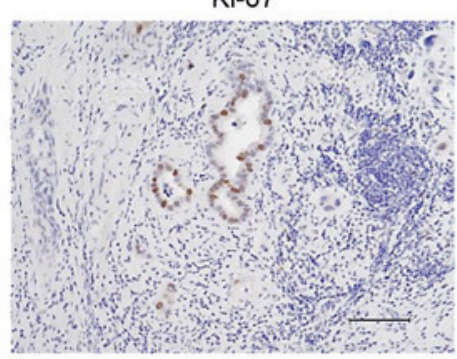

Ki-67

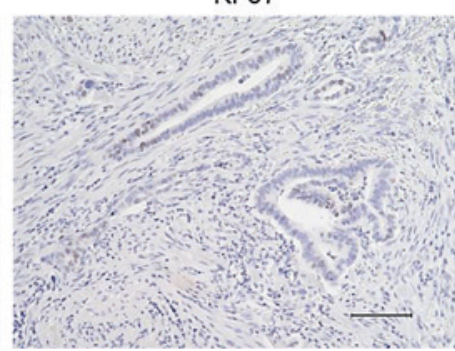

Figure 2. Correlation between FBXW7, c-Myc, and Ki-67 expression in representative cholangiocarcinoma tissue samples. Proteins were detected by immunohistochemistry. (A) Low levels of FBXW7 expression (left) in tumors exhibited enhanced c-Myc (middle) and Ki-67 (right) expression. (B) High FBXW7 expression (left) in tumors exhibited decreased c-Myc (middle) and Ki-67 (right) expression. Magnification, x200; scale bar, $100 \mu \mathrm{m}$. Immunohistochemical staining was performed using 3,3'-diaminobenzidine and counterstaining of the nucleus was performed using Mayer's hematoxylin solution. All bright images were obtained using a fluorescence microscope (BZ-X700, KEYENCE, Osaka, Japan) Ki-67, marker of proliferation Ki67; FBXW7, F-box and WD repeat domain-containing 7.

size and poor prognosis in patients with $\mathrm{CC}$, and is associated with enhanced c-Myc and Ki-67 expression. Furthermore, the efficacy of chemotherapy differed according to FBXW7 expression levels, as the low FBXW7 expression group was more sensitive to chemotherapy compared with the high FBXW7 expression group.

c-Myc is a target protein of FBXW7, and is regulated and degraded via ubiquitin-proteasome pathways. Therefore, 
Table II. Clinicopathological characteristics according to FBXW7 expression in 100 patients with cholangiocarcinoma.

\begin{tabular}{|c|c|c|c|}
\hline \multirow[b]{2}{*}{ Factors } & \multicolumn{2}{|c|}{ FBXW7 expression (\%) } & \multirow[b]{2}{*}{ P-value } \\
\hline & High $(n=54)$ & Low $(n=46)$ & \\
\hline Age & & & 0.684 \\
\hline$\leq 65$ & $35(64.8)$ & $28(60.9)$ & \\
\hline$>65$ & $19(35.2)$ & $18(39.1)$ & \\
\hline Sex & & & 0.450 \\
\hline Male & $39(72.2)$ & $30(65.2)$ & \\
\hline Female & $15(27.8)$ & $16(34.8)$ & \\
\hline Histology & & & 0.364 \\
\hline Well & $14(25.9)$ & $7(15.2)$ & \\
\hline Moderate & $26(48.2)$ & $23(50.0)$ & \\
\hline Poor & $14(25.9)$ & $16(34.8)$ & \\
\hline Location & & & 0.116 \\
\hline Distal & $42(77.8)$ & $31(67.4)$ & \\
\hline Perihilar & $8(14.8)$ & $5(10.9)$ & \\
\hline Intrahepatic & $4(7.4)$ & $10(21.7)$ & \\
\hline Tumor size (mm) & & & $0.049^{\mathrm{a}}$ \\
\hline$\leq 60$ & 47 (95.9) & $37(84.1)$ & \\
\hline$>60$ & $2(4.1)$ & $7(15.9)$ & \\
\hline Tumor stage & & & 0.515 \\
\hline $\mathrm{T} 1, \mathrm{~T} 2$ & $27(50.0)$ & $20(43.5)$ & \\
\hline $\mathrm{T} 3, \mathrm{~T} 4$ & $27(50.0)$ & $26(56.5)$ & \\
\hline Lymph node metastasis & & & 0.591 \\
\hline Absent & $30(55.6)$ & $28(60.9)$ & \\
\hline Present & $24(44.4)$ & $18(39.1)$ & \\
\hline Stage (UICC) & & & 0.249 \\
\hline $0, \mathrm{I}, \mathrm{II}$ & $44(81.5)$ & $33(71.7)$ & \\
\hline III, IV & $10(18.5)$ & $13(28.3)$ & \\
\hline Recurrence & & & 0.923 \\
\hline Absent & $24(44.4)$ & $20(43.5)$ & \\
\hline Present & $30(55.6)$ & $26(56.5)$ & \\
\hline Chemotherapy & & & 0.547 \\
\hline Absent & $18(33.3)$ & $18(39.1)$ & \\
\hline Present & $36(66.7)$ & $28(60.9)$ & \\
\hline Nuclear c-Myc accumulation & & & $<0.001^{\mathrm{a}}$ \\
\hline Negative & $42(77.8)$ & $17(37.0)$ & \\
\hline Positive & $12(22.2)$ & $29(63.0)$ & \\
\hline Recurrence free survival (Months) & & & $0.044^{\mathrm{a}}$ \\
\hline Median (range) & $12(0.5-123.0)$ & $7.6(0.3-83.0)$ & \\
\hline
\end{tabular}

FBXW7, F-box and WD repeat domain-containing 7; UICC, Union for International Cancer Control. ${ }^{\text {aP }}<0.05$ All P-values were obtained by comparison between high and low FBXW7 expression groups.

the loss of FBXW7 function results in the accumulation of c-Myc $(18,19)$. Additionally, as c-Myc serves an important role in cell cycle regulation, particularly in G0-G1 phase transition (20), the overexpression of c-Myc in tumors is associated with aggressive proliferation $(21,22)$. It has been demonstrated that hematopoietic stem cells from conditional $F B X W 7$ gene knockout mice exhibited c-Myc accumulation, and were therefore difficult to maintain in a quiescent state, leading to excessive acceleration of their cell cycle, exhaustion and even leukemogenesis (23). Additionally, the suppression of FBXW7 by small interference RNA in human colorectal cancer cell lines resulted in enhanced c-Myc expression and increased proliferation (24). In a previous study of clinical samples, low FBXW7 expression correlated with greater tumor size in 


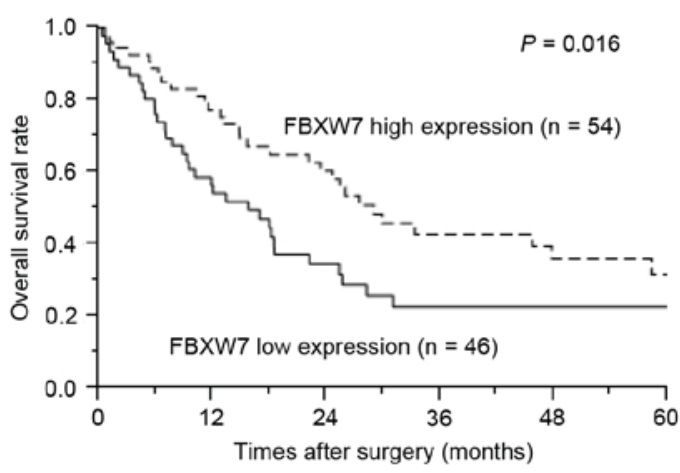

c

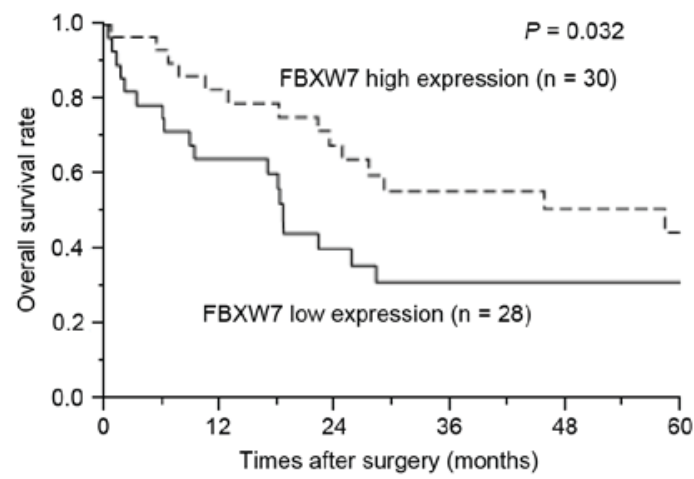

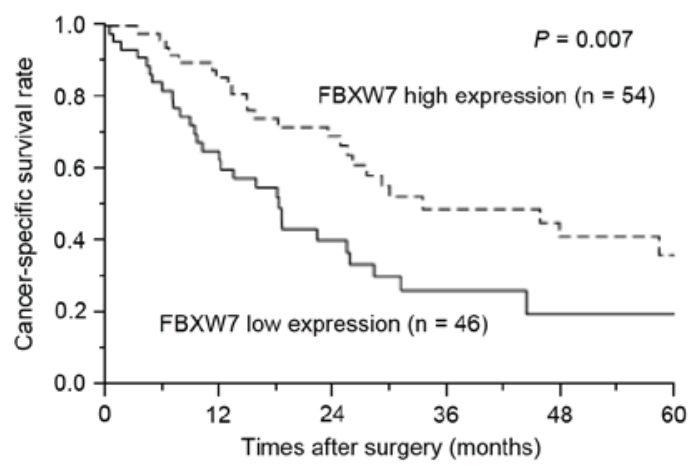

D

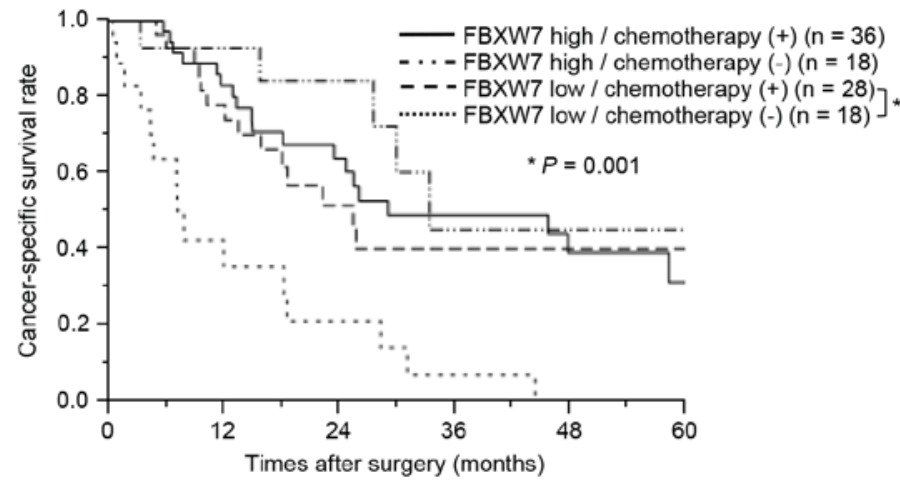

Figure 3. Kaplan-Meier curves of patients with cholangiocarcinoma according to FBXW7 expression. (A) Overall survival rate of patients with low FBXW7 expression was significantly lower compared with that of patients with high FBXW7 expression $(\mathrm{P}=0.016)$. (B) Cancer-specific survival rate of patients with low FBXW7 expression was also significantly lower compared with that of patients with high FBXW7 expression (P=0.007). (C) In cholangiocarcinoma patients without lymph node metastasis, patients with low FBXW7 expression exhibited poorer prognosis for overall survival compared with patients with high FBXW7 expression ( $\mathrm{P}=0.032$ ). (D) Cancer-specific survival rate according to the combination of FBXW7 expression and chemotherapy. In the high FBXW7 expression group, no significant difference was observed with respect to survival between patients with or without chemotherapy. In the low FBXW7 expression group, patients without chemotherapy exhibited poorer survival prognoses compared with patients who received chemotherapy ( $\mathrm{P}=0.001)$. FBXW7, F-box and WD repeat domain-containing 7.

gastric cancer and intrahepatic CC $(14,25)$. The present study was consistent with previous findings, as cancer tissue samples with low FBXW7 expression exhibited enhanced nuclear c-Myc and Ki-67 staining. Thus, the data of the present study suggest that the greater tumor sizes observed in the low FBXW7 expression group were caused by an acceleration of the cell cycle, and subsequently of proliferation, due to c-Myc accumulation.

Low levels of FBXW7 protein and/or messenger RNA were revealed to be associated with poor prognoses in breast $(10,26)$, gastric (25), non-small cell lung (27) and esophageal cancer $(12,13)$. The present study demonstrated that low FBXW7 expression in CC was an independent poor prognostic factor that outweighed existing clinicopathological factors, including TNM stage. Thus, the evaluation of FBXW7 expression is a potentially a useful marker for predicting prognosis in patients with CC.

Previously, molecular pathways that regulate FBXW7 stability and cellular functions have been investigated extensively. Gene mutation, copy number variations and transcriptional- and post-transcriptional controls are hypothesized to suppress FBXW7 function in cancer (28). FBXW7 gene alterations are often detected in human malignancies, with the rate identified to be $\sim 6 \%$ (29). As for mechanisms for the modification of FBXW7 activity other than gene alteration, previous studies have revealed that FBXW7 is regulated by p53 $(30,31)$, microRNA (miR-223 and miR-27) $(32,33)$ and self-ubiquitination in a phosphorylation-dependent manner $(34,35)$. The mutation rate of FBXW7 in CC is $\sim 15-35 \%$, which is as high as in patients with T-cell acute lymphoblastic leukemia $(36,37)$. These data suggest that $F B X W 7$ mutations serve an important role in CC development, and are one of the important suppression mechanisms of FBXW7 in CC. However, the association between FBXW7 mutations and FBXW7 protein expression, as evaluated by immunohistochemistry in the present study, remains unclear and requires additional investigation.

Previous studies have examined the association between FBXW7 and chemosensitivity. It was demonstrated that low FBXW7 expression produced resistance to anti-tubulin agents such as paclitaxel due to MCL1 accumulation $(9,27)$. Additionally, another report revealed that low FBXW7 expression is associated with resistance to doxorubicin in hepatocellular carcinoma (38). However, FBXW7 depletion in leukemia-initiating cells of chronic myeloid leukemia promotes cell cycle re-entry through c-Myc accumulation, and leads to the high sensitivity to imatinib in leukemia-initiating cells and thus enhanced eradication (8). Thus, FBXW7 has a dichotomous 
Table III. Association between clinicopathological characteristics and chemotherapy in patients with low FBXW7 expression.

\begin{tabular}{|c|c|c|c|}
\hline \multirow[b]{2}{*}{ Factors } & \multicolumn{2}{|c|}{ Chemotherapy (\%) } & \multirow[b]{2}{*}{ P-value } \\
\hline & Absent $(\mathrm{n}=18)$ & Present $(n=28)$ & \\
\hline Age & & & 0.554 \\
\hline$\leq 65$ & $8(44.4)$ & $10(35.7)$ & \\
\hline$>65$ & $10(55.6)$ & $18(64.3)$ & \\
\hline Sex & & & 0.639 \\
\hline Male & $11(61.1)$ & $19(67.9)$ & \\
\hline Female & $7(38.9)$ & $9(32.1)$ & \\
\hline Histology & & & 0.833 \\
\hline Well & $3(16.7)$ & $4(14.3)$ & \\
\hline Moderate & $8(44.4)$ & $15(53.6)$ & \\
\hline Poor & 7 (38.9) & $9(32.1)$ & \\
\hline Tumor size (mm) & & & 0.697 \\
\hline$\leq 60$ & $13(81.3)$ & $24(85.7)$ & \\
\hline$>60$ & $3(18.7)$ & $4(14.3)$ & \\
\hline Tumor stage & & & 0.474 \\
\hline $\mathrm{T} 1, \mathrm{~T} 2$ & $9(50.0)$ & $11(39.3)$ & \\
\hline $\mathrm{T} 3, \mathrm{~T} 4$ & $9(50.0)$ & $17(60.7)$ & \\
\hline Lymph node metastasis & & & 0.554 \\
\hline Absent & $10(55.6)$ & $18(64.3)$ & \\
\hline Present & $8(44.4)$ & $10(35.7)$ & \\
\hline Stage (UICC) & & & 0.954 \\
\hline $0, \mathrm{I}, \mathrm{II}$ & $13(72.2)$ & $20(71.4)$ & \\
\hline III, IV & $5(27.8)$ & $8(28.6)$ & \\
\hline
\end{tabular}

UICC, Union for International Cancer Control.

Table IV. Univariate and Multivariate analysis for overall survival using the Cox proportional hazards model.

\begin{tabular}{|c|c|c|c|c|c|c|}
\hline \multirow[b]{2}{*}{ Variable } & \multicolumn{3}{|c|}{ Univariate analysis } & \multicolumn{3}{|c|}{ Multivariate analysis } \\
\hline & HR & $95 \% \mathrm{CI}$ & $\mathrm{P}$-value & HR & $95 \% \mathrm{CI}$ & P-value \\
\hline $\operatorname{Age}(\leq 65$ vs. $>65)$ & 1.23 & $0.74-2.00$ & 0.404 & - & - & - \\
\hline \multicolumn{7}{|l|}{ Sex (Male vs. } \\
\hline Female) & 1.25 & $0.75-2.15$ & 0.379 & - & - & - \\
\hline \multicolumn{7}{|l|}{ Histology (Well vs. } \\
\hline Moderately vs. Poor) & 2.52 & $1.33-5.31$ & $0.004^{\mathrm{a}}$ & 1.83 & $0.93-3.96$ & 0.082 \\
\hline Tumor stage (T1-2 vs. T3-4) & 2.07 & $1.26-3.45$ & $0.004^{\mathrm{a}}$ & 1.57 & $0.91-2.75$ & 0.101 \\
\hline \multicolumn{7}{|l|}{ Lymph node } \\
\hline metastasis (- vs. +) & 1.86 & $1.14-3.14$ & $0.014^{\mathrm{a}}$ & 1.4 & $0.80-2.46$ & 0.229 \\
\hline Recurrence (- vs. +) & 2.24 & $1.32-3.97$ & $0.002^{\mathrm{a}}$ & 1.56 & $0.90-2.82$ & 0.598 \\
\hline FBXW7 (High vs. Low) & 1.81 & $1.10-2.97$ & $0.018^{\mathrm{a}}$ & 1.67 & $1.01-2.76$ & $0.043^{\mathrm{a}}$ \\
\hline
\end{tabular}

HR, hazard ratio; CI, confidence interval; FBXW7, F-box and WD repeat domain-containing 7. ${ }^{\mathrm{P}}<0.05$.

role with respect to chemosensitivity (39). In the present study, the cancer-specific survival in patients with $\mathrm{CC}$ with low FBXW7 expression levels who underwent chemotherapy exhibited improved prognosis compared with patients who did not, despite there being no difference in outcomes according to chemotherapy administration in patients with $\mathrm{CC}$ with high FBXW7 levels (Fig. 3D). c-Myc accumulation and increased Ki-67 positive cells were also confirmed in the low FBXW7 
expression group. Notably, it was demonstrated that the overexpression of c-Myc sensitized pancreatic cancer cell lines to cisplatin (40), and that pediatric medulloblastoma cells are sensitive to chemo- and radiation therapy because of their high c-Myc expression (41). Based on these observations, it appears that c-Myc accumulation as regulated by FBXW7 induces chemosensitivity in patients with clinical CC. The evaluation of FBXW7 expression in CC clinical samples may contribute to predicting the efficacy of chemotherapy and selecting those patients who are expected to benefit from it.

The present study had several limitations, including the retrospective design, single-center cohort and disease heterogeneity, such as intra- and extrahepatic disease, and heterogeneous treatment groups. In particular, as aforementioned, a sample bias of patients according to receipt of chemotherapy was an important issue in the present study, as patients who did not wish to undergo chemotherapy were excluded from the adaptation criteria of chemotherapy. Accordingly, additional studies in larger series, preferably prospective multi-center cohorts, are required to confirm these data.

In conclusion, low expression levels of the cell cycle regulator and tumor suppressor FBXW7 contributed to shorter survival and greater tumor size in patients with $C C$. The evaluation of FBXW7 expression levels may therefore be a useful predictor of poor prognosis and cancer progression in $\mathrm{CC}$, particularly extrahepatic $\mathrm{CC}$, considering the cohort of the present study. Conversely, low FBXW7 expression was associated with prolonged survival times in patients with $\mathrm{CC}$ treated by chemotherapy; this suggests that FBXW7 may be a surrogate marker for predicting the efficacy of chemotherapy in $\mathrm{CC}$.

\section{Acknowledgements}

The present study was supported by Grants-in-Aid for Scientific Research from the Japan Society for the Promotion of Science (JSPS; grant numbers 26461969, 15K10129 and 15K10085). The present study was also supported in part by Uehara Zaidan, the Medical Research Encouragement Prize of The Japan Medical Association, the Promotion Plan for the Platform of Human Resource Development for Cancer and New Paradigms - Establishing Centers for Fostering Medical Researchers of the Future programs by the Ministry of Education, Culture, Sports, Science, and Technology of Japan, and Gunma University Initiative for Advanced Research (GIAR).

\section{References}

1. Rizvi S and Gores GJ: Pathogenesis, diagnosis and management of cholangiocarcinoma. Gastroenterology 145: 1215-1229, 2013.

2. Blechacz B and Gores GJ: Cholangiocarcinoma: Advances in pathogenesis, diagnosis and treatment. Hepatology 48: 308-321, 2008.

3. Valle JW: Advances in the treatment of metastatic or unresectable biliary tract cancer. Ann Oncol 21 Suppl 7: vii345-vii348, 2010.

4. Valle JW, Furuse J, Jitlal M, Beare S, Mizuno N, Wasan H, Bridgewater $\mathrm{J}$ and Okusaka T: Cisplatin and gemcitabine for advanced biliary tract cancer: A meta-analysis of two randomised trials. Ann Oncol 25: 391-398, 2014.

5. Davis RJ, Welcker M and Clurman BE: Tumor suppression by the Fbw7 ubiquitin ligase: Mechanisms and opportunities. Cancer Cell 26: 455-464, 2014.

6. Tan Y, Sangfelt O and Spruck C: The Fbxw7/hCdc4 tumor suppressor in human cancer. Cancer Lett 271: 1-12, 2008.
7. Onoyama I and Nakayama KI: Fbxw7 in cell cycle exit and stem cell maintenance: Insight from gene-targeted mice. Cell Cycle 7: 3307-3313, 2008.

8. Takeishi S, Matsumoto A, Onoyama I, Naka K, Hirao A and Nakayama KI: Ablation of Fbxw7 eliminates leukemia-initiating cells by preventing quiescence. Cancer Cell 23: 347-361, 2013.

9. Wertz IE, Kusam S, Lam C, Okamoto T, Sandoval W, Anderson DJ, Helgason E, Ernst JA, Eby M, Liu J, et al: Sensitivity to antitubulin chemotherapeutics is regulated by MCL1 and FBW7. Nature 471: 110-114, 2011.

10. Ibusuki M, Yamamoto Y, Shinriki S, Ando Y and Iwase H: Reduced expression of ubiquitin ligase FBXW7 mRNA is associated with poor prognosis in breast cancer patients. Cancer Sci 102: 439-445, 2011.

11. Imura S, Tovuu LO, Utsunomiya T, Morine $Y$, Ikemoto $T$, Arakawa Y, Kanamoto M, Iwahashi S, Saito Y, Takasu C, et al: The role of Fbxw7 expression in hepatocellular carcinoma and adjacent non-tumor liver tissue. J Gastroenterol Hepatol 29: 1822-1829, 2014.

12. Yokobori T, Mimori K, Iwatsuki M, Ishii H, Tanaka F, Sato T, Toh H, Sudo T, Iwaya T, Tanaka Y, et al: Copy number loss of FBXW7 is related to gene expression and poor prognosis in esophageal squamous cell carcinoma. Int J Oncol 41: 253-259, 2012.

13. Kurashige J, Watanabe M, Iwatsuki M, Kinoshita K, Saito S, Hiyoshi Y, Kamohara H, Baba Y, Mimori K and Baba H: Overexpression of microRNA-223 regulates the ubiquitin ligase FBXW7 in oesophageal squamous cell carcinoma. Br J Cancer 106: 182-188, 2012.

14. Yang H, Lu X, Liu Z, Chen L, Xu Y, Wang Y, Wei G and Chen Y: FBXW7 suppresses epithelial-mesenchymal transition, stemness and metastatic potential of cholangiocarcinoma cells. Oncotarget 6: 6310-6325, 2015.

15. Enkhbold C, Utsunomiya T, Morine Y, Imura S, Ikemoto T, Arakawa Y, Kanamoto M, Iwahashi S, Saito Y, Ishikawa D and Shimada M: Loss of FBXW7 expression is associated with poor prognosis in intrahepatic cholangiocarcinoma. Hepatol Res 44: E346-E352, 2014.

16. TNM classification of malignant tumors. Int Union Again Cancer (UICC): 7th ed. New York: Wiley-Liss; 2009.

17. Huang W, Guo L, Liu H, Zheng B, Ying J and Lv N: C-MYC overexpression predicts aggressive transformation and a poor outcome in mucosa-associated lymphoid tissue lymphomas. Int J Clin Exp Pathol 7: 5634-5644, 2014.

18. Welcker M, Orian A, Jin J, Grim JE, Harper JW, Eisenman RN and Clurman BE: The Fbw7 tumor suppressor regulates glycogen synthase kinase 3 phosphorylation-dependent c-Myc protein degradation. Proc Natl Acad Sci USA 101: 9085-9090, 2004.

19. Yada M, Hatakeyama S, Kamura T, Nishiyama M, Tsunematsu R, Imaki H, Ishida N, Okumura F, Nakayama K and Nakayama KI: Phosphorylation-dependent degradation of c-Myc is mediated by the F-box protein Fbw7. EMBO J 23: 2116-2125, 2004.

20. Singh AM and Dalton S: The cell cycle and Myc intersect with mechanisms that regulate pluripotency and reprogramming. Cell Stem Cell 5: 141-149, 2009.

21. Spencer CA and Groudine M: Control of c-myc regulation in normal and neoplastic cells. Adv Cancer Res 56: 1-48, 1991.

22. Grandori C, Cowley SM, James LP and Eisenman RN: The Myc/Max/Mad network and the transcriptional control of cell behavior. Annu Rev Cell Dev Biol 16: 653-699, 2000.

23. Matsuoka S, Oike Y, Onoyama I, Iwama A, Arai F, Takubo K, Mashimo Y, Oguro H, Nitta E, Ito K, et al: Fbxw7 acts as a critical fail-safe against premature loss of hematopoietic stem cells and development of T-ALL. Genes Dev 22: 986-991, 2008.

24. Iwatsuki M, Mimori K, Ishii H, Yokobori T, Takatsuno Y, Sato T, Toh H, Onoyama I, Nakayama KI, Baba H and Mori M: Loss of FBXW7, a cell cycle regulating gene, in colorectal cancer: Clinical significance. Int J Cancer 126: 1828-1837, 2010.

25. Yokobori T, Mimori K, Iwatsuki M, Ishii H, Onoyama I, Fukagawa T, Kuwano H, Nakayama KI and Mori M: P53-Altered FBXW7 expression determines poor prognosis in gastric cancer cases. Cancer Res 69: 3788-3794, 2009.

26. Mao JH, Kim IJ, Wu D, Climent J, Kang HC, DelRosario R and Balmain A: FBXW7 targets mTOR for degradation and cooperates with PTEN in tumor suppression. Science 321: 1499-1502, 2008.

27. Yokobori T, Yokoyama Y, Mogi A, Endoh H, Altan B, Kosaka T, Yamaki E, Yajima T, Tomizawa K, Azuma Y, et al: FBXW7 mediates chemotherapeutic sensitivity and prognosis in NSCLCs. Mol Cancer Res 12: 32-37, 2014.

28. Wang L, Ye X, Liu Y, Wei W and Wang Z: Aberrant regulation of FBW7 in cancer. Oncotarget 5: 2000-2015, 2014. 
29. Akhoondi S, Sun D, von der Lehr N, Apostolidou S, Klotz K Maljukova A, Cepeda D, Fiegl H, Dafou D, Marth C, et al: FBXW7/hCDC4 is a general tumor suppressor in human cancer. Cancer Res 67: 9006-9012, 2007.

30. Kimura T, Gotoh M, Nakamura Y and Arakawa H: HCDC4b, a regulator of cyclin $\mathrm{E}$, as a direct transcriptional target of $\mathrm{p} 53$. Cancer Sci 94: 431-436, 2003.

31. Mao JH, Perez-Losada J, Wu D, Delrosario R, Tsunematsu R, Nakayama KI, Brown K, Bryson S and Balmain A: Fbxw7/Cdc4 is a p53-dependent, haploinsufficient tumour suppressor gene. Nature 432: 775-779, 2004

32. Xu Y, Sengupta T, Kukreja L and Minella AC: MicroRNA-223 regulates cyclin $\mathrm{E}$ activity by modulating expression of F-box and WD-40 domain protein 7. J Biol Chem 285: 34439-34446, 2010.

33. Lerner M, Lundgren J, Akhoondi S, Jahn A, Ng HF, Akbari Moqadam F, Oude Vrielink JA, Agami R, Den Boer ML, Grandér D and Sangfelt O: MiRNA-27a controls FBW7/hCDC4-dependent cyclin E degradation and cell cycle progression. Cell Cycle 10: 2172-2183, 2011.

34. Min SH, Lau AW, Lee TH, Inuzuka H, Wei S, Huang P, Shaik $S$, Lee DY, Finn G, Balastik M, et al: Negative regulation of the stability and tumor suppressor function of Fbw7 by the Pin1 prolyl isomerase. Mol Cell 46: 771-783, 2012

35. Ji S, Qin Y, Shi S, Liu X, Hu H, Zhou H, Gao J, Zhang B, Xu W, Liu J, et al: ERK kinase phosphorylates and destabilizes the tumor suppressor FBW7 in pancreatic cancer. Cell Res 25: $561-573,2015$.

36. Cheng Y and Li G: Role of the ubiquitin ligase Fbw7 in cancer progression. Cancer Metastasis Rev 31: 75-87, 2012.
37. Churi CR, Shroff R, Wang Y, Rashid A, Kang HC, Weatherly J, Zuo M, Zinner R, Hong D, Meric-Bernstam F, et al: Mutation profiling in cholangiocarcinoma: Prognostic and therapeutic implications. PLoS One 9: e115383, 2014.

38. Yu J, Zhang W, Gao F, Liu YX, Chen ZY, Cheng LY, Xie SF and Zheng SS: FBW7 increases chemosensitivity in hepatocellular carcinoma cells through suppression of epithelial-mesenchymal transition. Hepatobiliary Pancreat Dis Int 13: 184-191, 2014.

39. Wang Z, Fukushima H, Gao D, Inuzuka H, Wan L, Lau AW, Liu P and Wei W: The two faces of FBW7 in cancer drug resistance. BioEssays 33: 851-859, 2011.

40. Biliran H Jr, Banerjee S, Thakur A, Sarkar FH, Bollig A, Ahmed F, Wu J, Sun Y and Liao JD: C-Myc-induced chemosensitization is mediated by suppression of cyclin D1 expression and nuclear factor-kappa B activity in pancreatic cancer cells. Clin Cancer Res 13: 2811-2821, 2007.

41. von Bueren AO, Oehler C, Shalaby T, von Hoff K, Pruschy M, Seifert B, Gerber NU, Warmuth-Metz M, Stearns D, Eberhart CG, et al: C-MYC expression sensitizes medulloblastoma cells to radio- and chemotherapy and has no impact on response in medulloblastoma patients. BMC Cancer 11: 74, 2011. 